\title{
BMJ Open A descriptive study of access to services in a random sample of Canadian rural emergency departments
}

\author{
Richard Fleet, ${ }^{1,2}$ Julien Poitras, ${ }^{1,2}$ Julie Maltais-Giguère, ${ }^{2}$ Julie Villa, ${ }^{2}$ \\ Patrick Archambault ${ }^{1,2}$
}

To cite: Fleet R, Poitras J, Maltais-Giguère $\mathrm{J}$, et al. A descriptive study of access to services in a random sample of Canadian rural emergency departments. BMJ Open 2013;3:e003876. doi:10.1136/bmjopen-2013003876

- Prepublication history and additional material for this paper is available online. To view these files please visit the journal online (http://dx.doi.org/10.1136/ bmjopen-2013-003876).

Meetings Results have been presented as a moderated poster at the 2012 CAEP conference (2-6 June 2012) in Niagara Falls, Ontario, Canada (Volume 14; S1 of CJEM) and as an oral presentation at the Canadian Rural Health Research Society conference (25-27 October 2012) in Lévis, Québec, Canada.

Received 23 August 2013 Revised 18 October 2013 Accepted 23 October 2013

\section{CrossMark}

For numbered affiliations see end of article.

Correspondence to Professor Richard Fleet; rfleet@videotron.ca

\section{ABSTRACT}

Objective: To examine 24/7 access to services and consultants in a sample of Canadian rural emergency departments (EDs).

Design: Cross-sectional study-mixed methods (structured interview, survey and government data bases) with random sampling of hospitals.

Setting: Canadian rural EDs (rural small town (RST) definition-Statistics Canada).

Participants: 28\% (95/336) of Canadian rural EDs providing $24 / 7$ physician coverage located in hospitals with acute care hospitalisation beds.

Main outcome measures: General characteristics of the rural EDs, information about 24/7 access to consultants, equipment and services, and the proportion of rural hospitals more than $300 \mathrm{~km}$ from levels 1 and 2 trauma centres.

Results: Of the 336 rural EDs identified, 122 (36\%) were randomly selected and contacted. Overall, 95 EDs participated in the study (participation rate, $78 \%$ ). Hospitals had, on an average, 23 acute care beds, 7 ED stretchers and 13500 annual ED visits. The proportion of rural hospitals with local access to the following $24 / 7$ services was paediatrician, $5 \%$; obstetrician, $10 \%$; psychiatrist, $11 \%$; internist, $12 \%$; intensive care unit, $17 \%$; CT scanner, $20 \%$; surgeon, $26 \%$; ultrasound, $28 \%$; basic X-ray, $97 \%$ and laboratory services, $99 \%$. Forty-four per cent and $54 \%$ of the RST EDs were more than $300 \mathrm{~km}$ from a level 1 and level 2 trauma centre, respectively.

Conclusions: This is the first study describing the services available in Canadian rural EDs. Apart from basic laboratory and X-ray services, most rural EDs have limited access to consultants, advanced imaging and critical care services. A detailed study is needed to evaluate the impact of these limited services on patient outcomes, costs and interfacility transport demands.

\section{INTRODUCTION}

Approximately $20 \%$ of the Canadian population lives in rural or remote areas. ${ }^{1}$ Providing sustainable access to emergency care in these areas is challenging. ${ }^{2}$ In the context of limited resources and increased costs, there

\section{Strengths and limitations of this study}

- To the best of our knowledge, this is the first nationwide study examining access to services in Canada's rural EDs.

- The current study does not permit representative comparisons between provinces, since a sample of rural EDs was included in this study.

- The study did not examine patient outcomes in relation to the limited services provided in rural facilities.

have been increased efforts to regionalise and centralise healthcare services in rural Canada. ${ }^{3-6}$ This has resulted in local service cuts and hospital closings. ${ }^{5}$ Therefore, the current level of services offered in rural hospitals in Canada is unclear. Published data on the subject are scarce, and access to updated resource databases is limited and sensitive. ${ }^{7}$ Despite the accessibility clause of the Canada Health Act, ${ }^{8}$ the legislation overseeing the country's publically funded universal healthcare system, disparities in access to emergency care may exist.

Facing similar challenges, the USA developed, in 1997, the critical access hospital (CAH) programme to enhance access to healthcare in rural communities. ${ }^{9}$ This legislation enables CAHs to receive a cost-based reimbursement for medicare beneficiaries with the goal of financially stabilising hospitals in small and remote areas. The legislation also sought to enhance the quality by imposing credentialing and quality assurance requirements. Yet, despite the creation of this programme, recent reports showed that compared with non-CAHs, CAHs had fewer clinical capabilities, worse processes of care and higher mortality rates for acute myocardial infarction, congestive heart failure and pneumonia $^{9}$ and ischaemic stroke. ${ }^{10}$

To the best of our knowledge, no comparable Canadian study has been conducted. 
While the vast majority of US rural hospitals have 24/7 local access to a CT scanner $(94 \%),{ }^{11}$ surgical services $(87 \%)$ and a significant proportion of intensive care units (ICUs; 41\%), ${ }^{9}$ preliminary reports from Canada ${ }^{6} 12$ show that, at least in British Columbia (BC), less than $15 \%$ of rural emergency departments (EDs) have local $24 / 7$ access to these services.

Limited access to services in rural areas may preferentially impact the provision of quality emergency care. The principles of emergency medicine rest on timely diagnosis and definitive treatment of life-threatening or limb-threatening conditions. Timely access to diagnostic imaging and consultant support and tertiary trauma centres are essential components of emergency care. A lack of these services leads to an increased need for interfacility transport, with a resultant impact on staff, medical resources, technological support, transfer systems, local and referral centre resources, patient costs and patient safety. ${ }^{13}{ }^{14}$ Patient transfers also result in significant delays in providing definitive care ${ }^{15}$ particularly in rural communities. ${ }^{16-19}$ Moreover, in these communities, the risk of trauma and trauma death is greater than in urban areas, ${ }^{19-23}$ especially during the prehospital period. $^{21} 22$

The objective of this study was to examine and describe the current situation concerning access to comprehensive healthcare services in a sample $(25 \%)$ of Canadian rural hospitals.

\section{METHODS}

The protocol was submitted to our internal ethics review board (CHAU Hôtel-Dieu de Lévis) in June 2011. It was deemed not to require further ethics evaluation, based on the Tri-Council Policy Statement, as the research focused on the availability of services in public healthcare facilities and did not involve human participants.

\section{Selection of rural EDs}

We focused on rural EDs with 24/7 physician coverage at hospitals with acute care hospitalisation beds. To facilitate eventual comparisons with EDs elsewhere, we excluded community health centres and clinics, nursing stations, mobile health units and private facilities. We consulted the Division of Geography at Statistics Canada to use their definition of 'rural and small town' (RST ${ }^{24}$; see online supplementary appendix 1 ). Briefly, they consider RSTs 'towns and municipalities outside the commuting zone of larger urban centres (ie, outside the commuting zone of centres with a population of 10000 or more)'.

EDs in RST communities were then identified using the Guide to Canadian Healthcare Facilities. ${ }^{25}$ The hospitals' status was then confirmed with the provincial health ministries by phone or email. Furthermore, the list of RSTs where the participating centres were located was submitted to Statistics Canada for confirmation. In the end, 336 RST EDs were identified.

\section{Procedure for random sampling}

The complete list of the 336 rural EDs, stratified for the provinces and territories, was submitted to an independent biostatistician, who generated a list of randomly ordered hospitals within each stratum. Our objective was to obtain data from at least $25 \%$ of the hospitals in each province and territory. To allow for the refusal to participate, the first $36 \%(n=122)$ of the hospitals listed within each stratum were initially contacted.

\section{Data collection}

As a first step, we sought to obtain data on ED patient volumes, local $24 / 7$ access to consultant support, imaging services, access to ICU beds and the distance to designated levels 1 and 2 trauma centres (see Hameed et $a l^{26}$ for the definition and identification of trauma centres), which was calculated with Google Maps. ${ }^{27}$ This web-based mapping/geographic information system provides valid estimates of road distances at low cost, it has fewer usability problems than other similar systems, ${ }^{28}$ and it has been used previously in healthcare. ${ }^{29} 30$

Data were collected between July and December 2011 by research assistants as well as by medical students doing a research rotation. Data were collected from a questionnaire completed by the ED managers, and when necessary, a brief $(10 \mathrm{~min})$ telephone interview was administered to complete the missing data. Government databases and official websites (eg, those of provincial health ministries) were also used as sources of information.

\section{Data entry and analysis}

All data entry was verified by a second research assistant. Descriptive statistics are presented as percentages, means and SDs.

\section{RESULTS}

Of the 336 rural EDs that met the inclusion criteria, 122 $(36 \%)$ were initially contacted in order to obtain a final sample of at least $25 \%$ of the EDs in each province and territory. In total, 95 EDs (28\%) of Canadian rural EDs participated in the study (participation rate $=78 \%$ ). The proportions of rural EDs from each province and territory and the sociodemographic characteristics of the RSTs in question are presented in tables 1 and 2. The location of the participating EDs and that of levels 1 and 2 trauma centres are shown in figure 1 Data from Statistics Canada. ${ }^{31}$

See figure 1 in a separate digital file named Figure_1_map_Canada25.

The general characteristics of the rural EDs and the results concerning 24/7 access to services and consultants are presented in tables 3 and 4. To summarise, RST hospitals had, on an average, 23 acute care beds and $7 \mathrm{ED}$ stretchers and averaged 13500 annual ED visits. Apart from basic laboratory and X-ray services, the majority of the rural EDs had limited access to 
Table 1 Proportions of rural EDs included in the study by province or territory

\begin{tabular}{lrc}
\hline Province or territory & EDs (n) & $\begin{array}{l}\text { Proportion of rural } \\
\text { EDs included in the } \\
\text { study (\%) }\end{array}$ \\
\hline All & 95 & 28 \\
Alberta & 17 & 26 \\
British Columbia & 9 & 26 \\
Manitoba & 12 & 27 \\
New Brunswick & 3 & 27 \\
Ontario & 17 & 27 \\
Quebec & 7 & 27 \\
Saskatchewan & 13 & 27 \\
Nova Scotia & 5 & 29 \\
Newfoundland and & 8 & 35 \\
Labrador & & \\
Nunavut & 1 & 50 \\
Prince Edward Island & 1 & 100 \\
Northwest Territories & 1 & 100 \\
Yukon & 1 & 100 \\
\hline EDs, emergency departments. &
\end{tabular}

professional and ancillary services. Forty-four per cent and $54 \%$ of the RST EDs are more than $300 \mathrm{~km}$ from a level 1 and level 2 trauma centre, respectively.

\section{DISCUSSION}

To the best of our knowledge, this is the first nationwide study examining access to services in Canada's rural EDs. The results of this study pertaining to a random sample of Canada's rural EDs suggest that these EDs have limited 24/7 local access to a CT scanner, consultants and an ICU. A considerable proportion of these rural hospitals are more than $300 \mathrm{~km}$ from levels 1 and 2 trauma centres.

Although the current study does not permit representative comparisons between provinces, since a sample $(28 \%)$ of rural EDs was included in this study, we recently reported considerable differences in access to these services between BC and Quebec (QC). ${ }^{12}$ In short, $73 \%$ of QC's rural EDs have 24/7 access to a CT scanner compared with only $3 \%$ for BC. With respect to support services, $81 \%$ of QC's rural EDs have a 24/7 on-call general surgeon compared with $12 \%$ for BC. Also, a greater proportion of QC's rural EDs are supported by an ICU than of those in BC $(88 \%$ vs $15 \%)$. It is still unclear whether the level of services offered in rural EDs reflects ED volumes and how the availability of these services affects interfacility transport issues and patient outcomes. It is also not known how different provincial policies influence the availability of these services. Nevertheless, these findings suggest potential nationwide variations in access to emergency care services.

A somewhat surprising finding in our study was the limited access to CT scanners in Canadian rural hospitals. These results significantly contrast with findings from US rural hospitals. CT scanners play an important role in the diagnosis and early triage of patients with acute and sometimes life-threatening illnesses, including stroke, major trauma, head injury, pulmonary embolism and abdominal pain. Urban and community hospitals have almost universal access to CT scanners, and their use during ED visits has increased $330 \%$, from $3.2 \%$ of encounters in 1996 to $13.9 \%$ in $2007 .{ }^{32}$ Even if some of these examinations could be considered superfluous in the context of increased awareness of the risks of ionising radiation, ${ }^{33}$ some clinical situations clearly require emergent CT scanning, and many guidelines and clinical decision rules can better guide its use. ${ }^{34}$

The first CT scanner in a rural setting in Canada was installed in 1999 in Walkerton, Ontario, a town $160 \mathrm{~km}$ north of London (population of 5036 at the time) ${ }^{35}$ It was installed as part of a pilot study, which was cut short because of positive outcomes. It is unclear why, according to our study, $80 \%$ of rural EDs do not have access to this technology more than a decade later. If we conservatively estimate the CT scanning needs at the rural hospitals studied to be $10 \%$ of emergency visits, an average of 1346 patients would require an interfacility transfer for this test alone.

Likewise, the impact of the minimal level of consultant and critical care services provided in rural hospitals should be examined from a viewpoint akin to that for CT services. Two Canadian studies examining the relationship between interfacility transport requirements and rural hospital services showed that most transfers from rural hospitals are for CT scanning, orthopaedic care, neurological diseases, and general surgical and critical care services. ${ }^{36}$ While a nationwide prospective study on interfacility transport processes is awaited, several salient questions remain. How many patients can

Table 2 Sociodemographic characteristics of the rural small towns in which the participating EDs were located

\begin{tabular}{lrrr}
\hline Sociodemographic characteristic & Mean & SD & Range \\
\hline Population & 5781.89 & 7247.96 & $172-45212$ \\
Population density per km & 216.81 & 219.20 & $0.6-956.1$ \\
Median age of the population & 41.56 & 5.91 & $20.5-53.8$ \\
Median income (\$; people 15 years of age and over) & 23778.33 & 5772.15 & $3792-44885$ \\
Median income after tax (\$; people 15 years of age and over) & 21735.48 & 4641.68 & $3792-37985$ \\
\hline EDs, emergency departments. & &
\end{tabular}




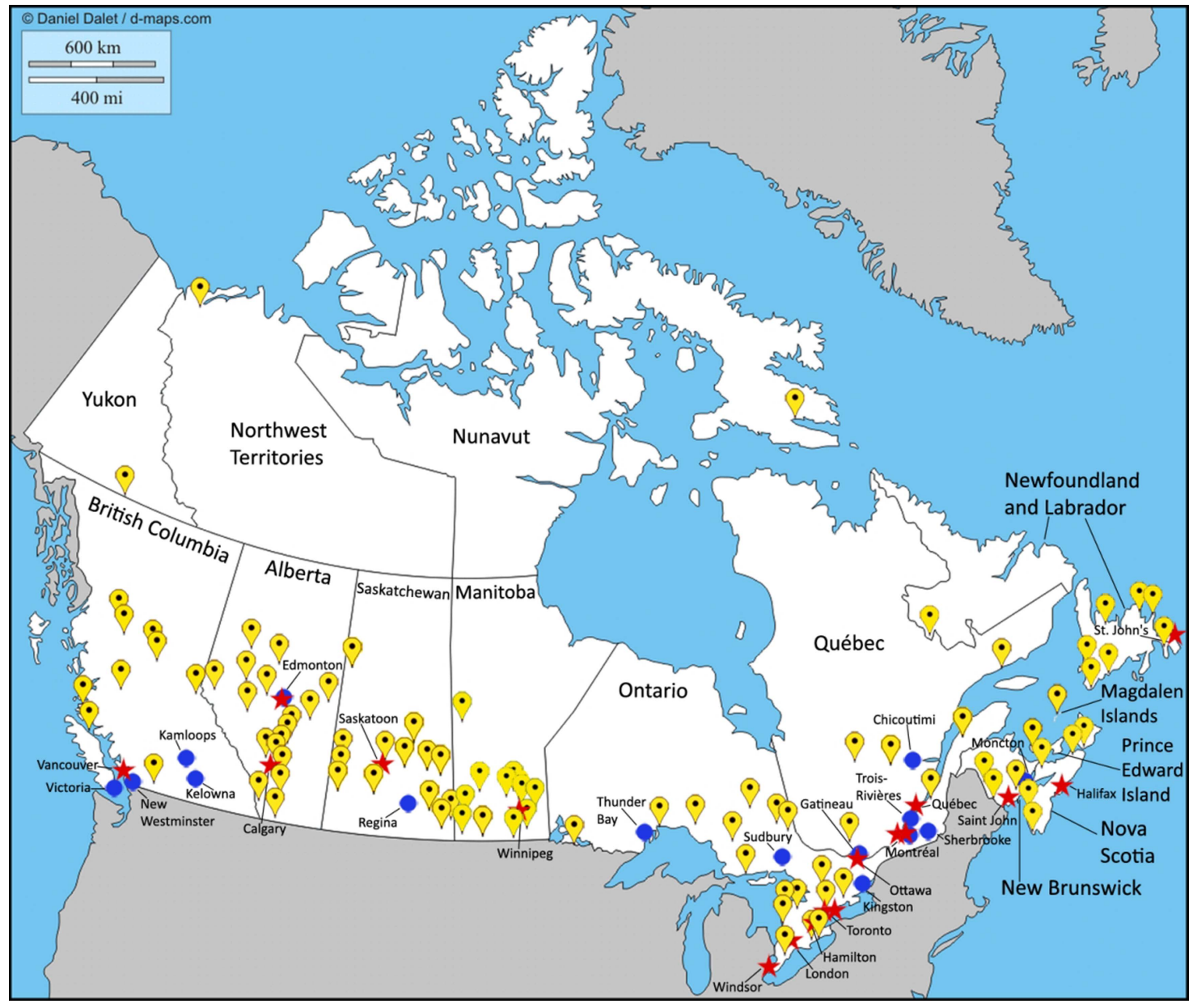

Figure 1 Location of the rural small town (RST) emergency departments (EDs) included in the study and that of levels 1 and 2 trauma centres. The RST EDs included in the study are identified on the map with yellow markers. Red stars represent level 1 trauma centres (see Hameed et $a^{p^{6}}$ for the definition of trauma centres). Blue circles represent level 2 trauma centres.

be safely managed in their communities? What reasonable level of local services should we provide to optimise the use of interfacility transport? As reported in this study, the limited level of services available in rural EDs likely requires more interfacility transport. How costeffective, timely and safe an alternative this is to providing more services rurally needs to be determined?

Table 3 General characteristics of the 95 Canadian rural EDs participating in the study

\begin{tabular}{ll}
\hline Annual ED patient visits (mean $\pm S D)$ & $13458 \pm 8853$ \\
ED stretchers (mean $\pm S D)$ & $6.8 \pm 3.9$ \\
Acute care beds (mean $\pm S D)$ & $23.0 \pm 17.7$ \\
Long-term beds (mean $\pm S D)$ & $18.7 \pm 23.8$ \\
Local ICU & $16.8 \%(n=16 / 95)$ \\
EDs $>300 \mathrm{~km}$ from a level 1 & $44.2 \%(n=42 / 95)$ \\
trauma centre & \\
EDs $>300 \mathrm{~km}$ from a level 2 & $54.4 \%(n=37 / 68)^{*}$ \\
trauma centre & \\
\hline${ }^{*}$ This proportion was calculated for 68 EDs because $27(28.4 \%$, \\
$\mathrm{n}=27 / 95)$ do not have access to a level 2 trauma centre, according \\
to Hameed et afs list.26 \\
ED, emergency department; ICU, intensive care unit.
\end{tabular}

Our finding that $44 \%$ of EDs are more than $300 \mathrm{~km}$ from a level 1 trauma centre and that $54 \%$ are more than $300 \mathrm{~km}$ from a level 2 trauma centre is troubling,

Table 4 Proportion of 24/7 access to consultants, equipment and services in the 95 Canadian rural EDs participating in the study

\begin{tabular}{lc}
\hline Consultants & Per cent $(\mathbf{n})$ \\
\hline Neurologist & $0(0 / 95)$ \\
Paediatrician & $5.3(5 / 95)$ \\
Orthopaedist & $6.3(6 / 95)$ \\
Obstetrician/gynaecologist & $9.5(9 / 95)$ \\
Psychiatrist & $10.5(10 / 95)$ \\
Internist & $11.6(11 / 95)$ \\
Surgeon & $26.3(25 / 95)$ \\
Equipment and services & \\
MRI & $2.1(2 / 95)$ \\
CT scanner & $20.0(19 / 95)$ \\
Ultrasound & $28.4(27 / 95)$ \\
Bedside ultrasound & $48.4(46 / 95)$ \\
Basic X-ray & $96.8(92 / 95)$ \\
Laboratory & $98.9(94 / 95)$ \\
\hline EDs, emergency departments. &
\end{tabular}


given the limited resources. There are clear benefits to managing trauma patients at these tertiary centres within the albeit debated timeframe of the 'golden hour'. ${ }^{38}$ However, these distances decrease the likelihood of patients obtaining this standard of care. Improving the level of local services and training of emergency professionals has been proposed as a solution to improving outcomes. Trauma care is particularly important in rural areas, where people are at greater risk for trauma and trauma death than their urban counterparts. ${ }^{19-23}$ For example, Gomez et $a l^{21}$ observed that this risk was threefold greater for Ontario's rural residents than for urban residents.

In order to legislate in favour of improved access to care in rural areas, evidence-based standards are required. The latest guidelines on the subject by the Canadian Association of Emergency Physicians were written in the context of healthcare cuts and associated risks for patients. ${ }^{39}$ This report was mainly based on expert opinion in the context of limited evidence on the subject at the time. The report did not make any specific recommendations as to the level of healthcare services that should be provided locally in rural EDs.

Meanwhile, the province of QC has published provincial guidelines with sections addressing rural emergency care. $^{40}$ The QC guide defines what support services an ED should receive, based on the hospital's designation. That designation is determined by several factors, including the annual number of patient visits. In 2006, this guide was revised with the goal of making all stakeholders accountable for quality of care in EDs. It is unclear whether QC has been successful in implementing these recommendations or whether they have led to an increased access to quality care. We are conducting a study to examine this issue. ${ }^{41}$

Finally, in light of these results, as well as those from the landmark study by Joynt $e t a l,{ }^{9}$ which showed poor outcomes for rural patients, Canadian healthcare professionals and decision-makers should be pressed to examine the impact of the current level of health services available in rural EDs on patient outcomes and begin to think about solutions so that Canadians can access quality care no matter where they reside or visit. Otherwise, the spirit of Canada's universal healthcare system, which is considered a defining feature of this country, would not be respected.

\section{LIMITATIONS}

This study relied on information provided through questionnaires and brief telephone interviews with local healthcare providers. Information was obtained mainly from one source, and cross-checking with other databases was not possible. However, the information requested was straightforward and probably easily accessed by professionals working in these small RST EDs.

To the best of our knowledge, the information obtained on $24 / 7$ access to services in this study is not easily or reliably accessible through standardised databases in Canada (Wu J. Program Lead, Decision Support Services, Clinical Administrative Databases, Canadian Institute for Health Information (CIHI). personal communication, 2013). Despite all the efforts to select a nationally representative sample of rural EDs from a random list for each province and territory, unique centres with higher or lower levels of local service resources may have been missed. Also, some hospitals may have refused to participate in the study because they are well equipped in terms of imaging or consulting services and may have been less interested in the project. However, the high overall participation rate minimises this potential selection bias.

Another limitation of our study is the lack of estimation of the travel time to levels 1 and 2 trauma centres in combination with the distance estimations. Total interfacility transfer times (call from rural EDs to arrival at levels 1 and 2 trauma centres) would better represent the care pathways of these patients factoring in weather, geography, roadwork and of course overall transport capabilities. We are planning such a study.

Finally, we reported population statistics on the RSTs where the hospitals were located. We did not obtain data on the hospitals' service areas. It would have been interesting to estimate the populations and the size of the territories served by theses rural hospitals. Our experience with this information in a pilot study is that it is difficult to reliably obtain and verify. ${ }^{12}$

\section{CONCLUSION}

This preliminary report on a national random sample of Canadian rural EDs suggests that there is limited access to advanced imaging and consultant services in these areas. A larger nationwide study is required to confirm these findings and permit meaningful interprovincial comparisons. Ultimately, a study aimed at examining the relationship between the level of service, interfacility transport requirements and patient outcomes is required. It would be helpful for provinces to uniformly collect, update and verify the data on the services provided in rural hospitals and to provide a better access to these databases.

\section{Author affiliations}

${ }^{1}$ Department of Family and Emergency Medicine, Université Laval, Quebec City, Quebec, Canada

${ }^{2}$ CHAU Hôtel-Dieu de Lévis Hospital, Lévis City, Quebec, Canada

Acknowledgements The authors would like to thank Jérémie Marcoux for his significant contribution to the literature research and data collection. They also wish to thank Sylvain Bussières, PhD for his help in reviewing an earlier version of the manuscript and graphics design as well as Mélodie-Anne Drouin for her significant contribution to the literature research and assistance in preparing the final version of the manuscript. Finally, they wish to thank Cynthia Fournier for her contribution in collecting sociodemographic data and Fatoumata Korika Tounkara for her help with the revised manuscript.

Contributors RF had the original idea, designed the study, drafted the first version of the manuscript and is responsible for the final version. JP and PA assisted with the study design, the literature research and editing of the manuscript. JV and JM-G contributed to the study coordination, data analysis 
and preparation of the manuscript. All authors contributed to and have approved the final manuscript.

Funding The research project was supported in part by a Junior 1 Clinician Scientist award from the FRQS (RF), the Research Chair in Emergency Medicine Laval University-CHAU Hôtel-Dieu de Lévis Hospital and the Hôtel-Dieu de Lévis Hospital research fund.

Competing interests None.

Provenance and peer review Not commissioned; externally peer reviewed.

Data sharing statement Data will not be automatically shared or distributed in a public forum. However, data will be made available on request to the corresponding author on a case-by-case basis.

Open Access This is an Open Access article distributed in accordance with the Creative Commons Attribution Non Commercial (CC BY-NC 3.0) license, which permits others to distribute, remix, adapt, build upon this work noncommercially, and license their derivative works on different terms, provided the original work is properly cited and the use is non-commercial. See: http:// creativecommons.org/licenses/by-nc/3.0/

\section{REFERENCES}

1. Statistics Canada. Canada's rural population since 1851-population and dwelling counts 2011 Census. Ottawa 2012.

2. Fleet R, Archambault $P$, Plant $J$, et al. Access to emergency care in rural Canada: should we be concerned? CJEM 2013;15:191-3.

3. McGregor J, Hanlon N, Emmons S, et al. If all ambulances could fly: putting provincial standards of emergency care access to the test in Northern British Columbia. Can J Rural Med 2005;10:163-8.

4. Ministries of Health Services and Health Planning. Standards of accessibility and guidelines for provision of sustainable acute care services by health authorities. Victoria: Government of British Columbia, 2002

5. Thompson JM, McNair NL. Health care reform and emergency outpatient use of rural hospitals in Alberta, Canada. J Emerg Med 1995;13:415-21.

6. Fleet R, Plant J, Ness R, et al. Patient advocacy by rural emergency physicians after major service cuts: the case of Nelson, BC. Can J Rural Med 2013;18:56-61.

7. Hildebrandt A. Provinces team up to block CBC's hospital data request-Cross-country denials raise questions about accountability, professor says. CBC News, 2013.

8. Minister of Justice. Canada Health Act. Ottawa: Government of Canada, 2012.

9. Joynt KE, Harris Y, Orav EJ, et al. Quality of care and patient outcomes in critical access rural hospitals. JAMA 2011;306:45-52.

10. Lichtman JH, Leifheit-Limson EC, Jones SB, et al. 30-Day risk-standardized mortality and readmission rates after ischemic stroke in critical access hospitals. Stroke 2012;43:2741-7.

11. Ginde AA, Foianini A, Renner DM, et al. Availability and quality of computed tomography and magnetic resonance imaging equipment in U.S. emergency departments. Acad Emerg Med 2008;15:780-3.

12. Fleet R, Audette LD, Marcoux J, et al. Comparison of access to services in rural emergency departments in Quebec and British Columbia. CJEM 2013;15:1-12.

13. Bosk EA, Veinot T, Iwashyna TJ. Which patients and where: a qualitative study of patient transfers from community hospitals. Med Care 2011;49:592-8.

14. Hains IM, Marks A, Georgiou A, et al. Non-emergency patient transport: what are the quality and safety issues? A systematic review. Int J Qual Health Care 2011;23:68-75.

15. Harrington DT, Connolly M, Biffl WL, et al. Transfer times to definitive care facilities are too long: a consequence of an immature trauma system. Ann Surg 2005;241:961-6; discussion 66-8.
16. Branas $\mathrm{C}$, Masckenzie $\mathrm{E}$, Williams J, et al. Access to trauma centers in the United States. JAMA 2005;293:2626-33.

17. Carr BG, Caplan JM, Pryor JP, et al. A meta-analysis of prehospital care times for trauma. Prehosp Emerg Care 2006;10:198-206.

18. Schuurman N, Bell N, Hameed MS, et al. A model for identifying and ranking need for trauma service in nonmetropolitan regions based on injury risk and access to services. J Trauma 2008;65:54-62.

19. Fatovich DM, Phillips M, Langford SA, et al. A comparison of metropolitan vs rural major trauma in Western Australia. Resuscitation 2011;82:886-90.

20. Fatovich DM, Jacobs IG. The relationship between remoteness and trauma deaths in Western Australia. J Trauma 2009;67:910-14.

21. Gomez D, Berube $M$, Xiong W, et al. Identifying targets for potential interventions to reduce rural trauma deaths: a population-based analysis. J Trauma 2010;69:633-9.

22. Simons R, Brasher P, Taulu T, et al. A population-based analysis of injury-related deaths and access to trauma care in rural-remote Northwest British Columbia. J Trauma 2010;69:11-19.

23. Bell N, Simons RK, Lakha N, et al. Are we failing our rural communities? Motor vehicle injury in British Columbia, Canada 2001-2007. Injury 2012;43:1888-91.

24. du Plessis V, Beshiri R, Bollman RD, et al. Definitions of rural. Rural and small town Canada analysis bulletin. Ottawa: Statistics Canada, 2001:1-17. Catalogue no.21-006-XIE.

25. Canadian Healthcare Association. Guide to Canadian healthcare facilities 2009-2010. Ottawa: CHA Press, 2009.

26. Hameed SM, Schuurman N, Razek T, et al. Access to trauma systems in Canada. J Trauma 2010;69:1350-61.

27. Google. Google maps. Secondary Google maps 2013. https://maps. google.ca/maps?hl=fr\&tab=Il

28. Nivala AM, Brewster S, Sarjakowski TL. Usability evaluation of web mapping sites. Cartographic J 2008;45:129-38.

29. Kobayashi S, Fujioka T, Tanaka $Y$, et al. A geographical information system using the Google Map API for guidance to referral hospitals. J Med Syst 2010;34:1157-60.

30. Masino $\mathrm{C}$, Rubinstein $\mathrm{E}$, Lem $\mathrm{L}$, et al. The impact of telemedicine on greenhouse gas emissions at an academic health science center in Canada. Telemed J E Health 2010;16:973-6.

31. Statistics Canada. 2006 Community Profiles. Secondary 2006 Community Profiles 2006. http://www12.statcan.ca/censusrecensement/2006/dp-pd/prof/92-591/index.cfm

32. Kocher KE, Meurer WJ, Fazel R, et al. National trends in use of computed tomography in the emergency department. Ann Emerg Med 2011;58:452-62 e3.

33. Griffey RT, Sodickson A. Cumulative radiation exposure and cancer risk estimates in emergency department patients undergoing repeat or multiple CT. AJR Am J Roentgenol 2009;192:887-92.

34. Haydon NB. Head injury: audit of a clinical guideline to justify head CT. J Med Imaging Radiat Oncol 2013;57:161-8.

35. Merkens B, Mowbray R, Creeden L, et al. A rural CT scanner: evaluating the effect on local health care. Can Assoc Radiol J 2006;57:224-31.

36. Rourke J, Kennard M. Emergency patient transfers from rural hospitals: a regional study. CJEM 2001;3:296-301.

37. De Freitas TL, Spooner GR, Szafran O. Admissions and transfers from a rural emergency department. Can Fam Physician 1998;44:789-95.

38. Fleet R, Poitras J. Have we killed the golden hour of trauma? Ann Emerg Med 2011;57:73-4; author reply 74-5.

39. Canadian Association of Emergency Physicians. Recommendations for the management of rural, remote and isolated emergency health care facilities in Canada. Ottawa: CAEP, 1997.

40. Ministère de la Santé et des Services sociaux du Québec. Guide de gestion de l'urgence. Québec: Gouvernement du Québec, 2006.

41. Fleet $\mathrm{R}$, Archambault $\mathrm{P}$, Legare $\mathrm{F}$, et al. Portrait of rural emergency departments in Quebec and utilisation of the Quebec Emergency Department Management Guide: a study protocol. BMJ Open 2013;3:pii: e002961. 